\title{
STUDY OF SEED CORN THRESHING PROCESS
}

\section{Dmitriy Bakharev, Alexander Pastukhov, Sergey Volvak, Sergey Kovalev}

Belgorod State Agricultural University named after V. Gorin, Russia

baharevdn_82@mail.ru, pastukhov_ag@mail.ru,volvak.s@yandex.ru, dasergeykovalev@rambler.ru

\begin{abstract}
A high yield of grain and green mass of corn can be obtained only when using the seeds of the first generation of zoned hybrids, which are threshed in the conditions of processing enterprises after pre-drying the cobs to a humidity of $12 \ldots 18 \%$. At this humidity, the strength of the shell of corn grains is maximal and the connection of the grain with the rod is weakened, which allows for threshing with minimal damage to the grain. An experimental design of an axial-rotary threshing device, which rotor is equipped with multi-helical spiral winding of variable height, is developed. The winding height decreases from the entrance to the threshing chamber to the exit from it. Rotor fully covered pneumatic-adaptive studded deck is installed so that the gap between the rotor shaft and the independent movable pins decreases from the input to the output. All pins are pressed against the deck by means of rubber pneumatic bags with an internal overpressure. In addition, the threshing chamber has the ability to change its spatial position relative to the horizon. These dimensional characteristics are justified foe a stationary axial-rotary threshing device with a productivity of up to $4.5 \mathrm{t} \cdot \mathrm{h}^{-1}$. As the result of experimental studies, the following rational intervals of values of the modes of operation of the threshing device were established: the rotor speed $150 \ldots 170 \mathrm{~min}^{-1}$, the angle of inclination of the threshing chamber $10 \ldots 14^{\circ}$, the force of pressing the movable pins to the cobs $35 \ldots .55 \mathrm{~N}$, feed $0.8 \ldots 1.1 \mathrm{~kg} \cdot \mathrm{s}^{-1}$. As a result, the productivity of the axial-rotary threshing device is in the range $2.88 \ldots 3.96 \mathrm{t} \cdot \mathrm{h}^{-1}$ and the energy intensity of the threshing process is $0.5 \ldots 0.7 \mathrm{kWh} \cdot \mathrm{t}^{-1}$, grain on the cob after threshing is less than $1.5 \%$, free grain in threshed corn cobs $1.16 \%$.
\end{abstract}

Keywords: corn, threshing device, rotor, deck, productivity, energy intensity.

\section{Introduction}

The production of quality seeds is one of the most important problems that FAO solves. The research is aimed at developing a base of scientific and practical knowledge about mechanized technologies for threshing cobs of seed corn.

Primary seed production of corn requires a technical solution to minimize macro-and microdamage to the grain of seed corn during threshing. For this purpose, threshing devices are improved and introduced into production, the working bodies of which are automatically adapted to continuously changing working conditions. In practice, the roller and disk adaptive threshing devices for seed corn are most often used. The productivity of these structures is limited by their design and technological parameters. The solution to the problem of increasing the productivity of threshing devices for seed corn lies in the field of creating rotary threshing systems.

In the process of solving the problem of minimizing the number of macro - and micro- damages to seed grain corn during threshing, an axial-rotary threshing device with pneumatic adaptive deck was theoretically justified and designed, the design and operation of which are described in detail in the source [1].

The purpose of the study is to determine the practical operation modes of an experimental axialrotor threshing device with a pneumatic adaptive deck, which provide the maximum possible productivity and high quality of threshing.

Technological and quality indicators characterize the efficiency of threshing devices for cobs of seed corn. Technological indicators include productivity, power consumption, and energy intensity of the threshing process. Quality indicators include the amount of grain remaining on the cobs after threshing, the amount of free grain in the threshed cobs, the total amount of grain with macro-and micro- damages in the threshed batch [2-5]. The list and methods for determining these indicators are described in GOST R 54779-2011 Corn harvesting combines. Test methods, as well as technical specifications for the production of selective corn harvesters and stationary corn threshers.

The numerical values of the above-described indicators depend significantly on two main factors: the rotation frequency of the rotor and the mass of cobs fed in the thresher [2-4]. To ensure highquality threshing, the values of these factors must be rational, which is determined as a result of search experiments.

For the purpose of experimental determination of rational values of these factors, an axial-rotary threshing device with pneumatic adaptive deck was constructed. The experimental design of the axial- 
rotary threshing device with a rotor length of $1350 \mathrm{~mm}$, a shaft diameter of $320 \mathrm{~mm}$, on which a multihelix spiral winding is fixed, the height of which varies from entrance to exit within $50-15 \mathrm{~mm}$, is developed. The rotor is covered by a $360^{\circ}$ pneumatic-adaptive studded deck, installed so that the gap between the rotor shaft and the independent movable pins varies from the input to the output within $70-20 \mathrm{~mm}$. All pins are pressed against the deck by means of rubber pneumatic bags with an internal pressure of 0.4 atmospheres. In addition, the threshing chamber has the ability to change its position relative to the horizon at an angle from 0 to $25^{\circ}$. The cobs are fed to the threshing machine parallel to the rotor axis by means of a loader and an orienting device. As a result of the mutual action of the rotor and the pneumatic-adaptive studded deck, the grain is separated from the cobs without damage and is passing into the grain hopper, and the threshed cobs exit through the discharge window located in the back of the device (Fig. 1).

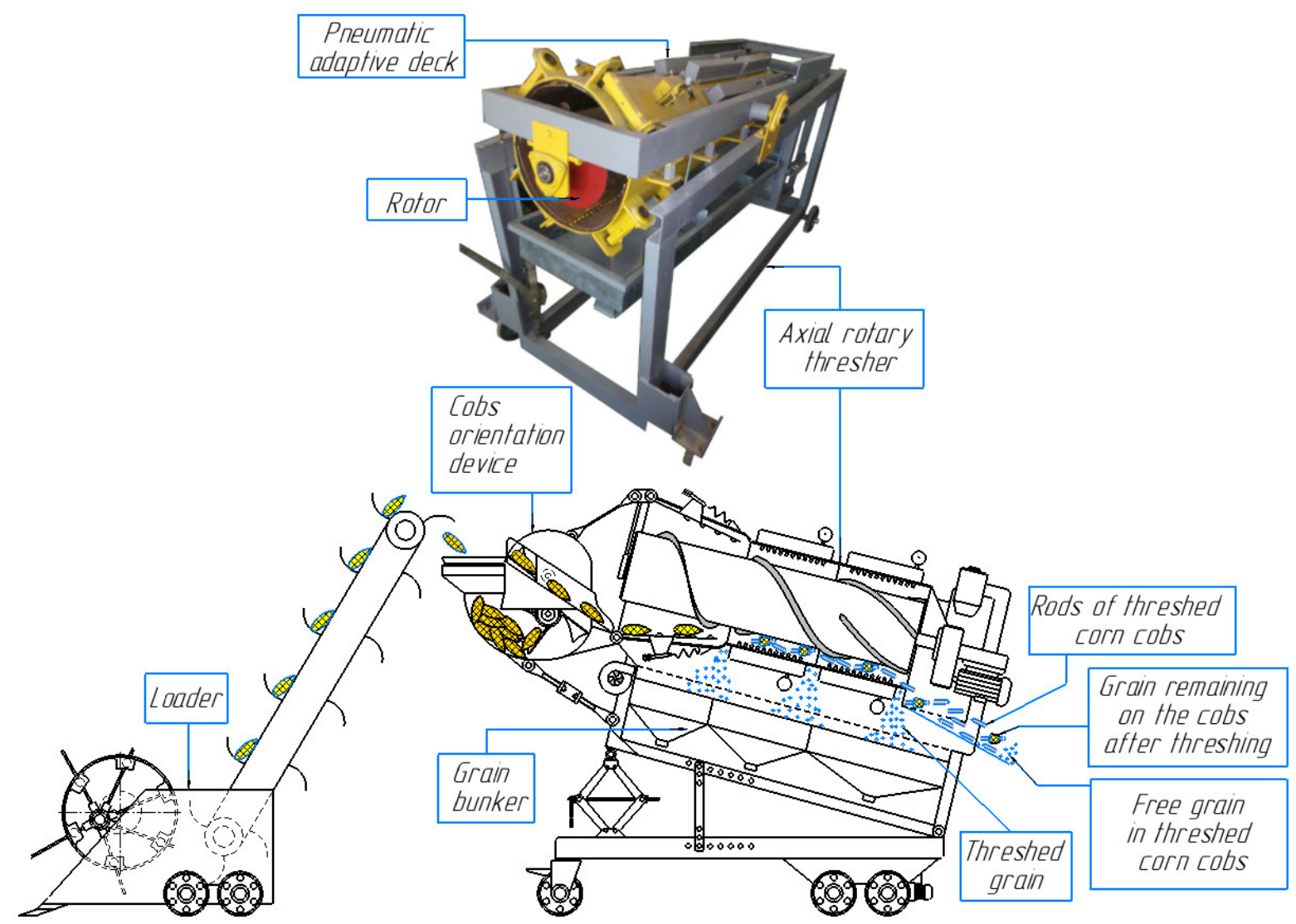

Fig. 1. Axial rotary threshing device with pneumatic adaptive deck

\section{Materials and methods}

The experiments were carried out with corn varieties CADR $267 \mathrm{MV}$. The grain humidity in the threshed cobs was within 12-18\%, which was controlled by a certified portable moisture meter immediately before the experiments. The research used single factor search experiments. The results were statistically processed using computer programs.

The following method of experiments was used:

- the threshing chamber was installed at an angle to the horizon of $12^{\circ}$ [1];

- on the deck of the threshing device 14 rubber pneumatic bags fixing 22 independent movable pins with a diameter of $12 \mathrm{~mm}$ were installed. The pressure force was provided for pins to cobs equal $35-55 \mathrm{~N}$.

- using a compressor in each rubber pneumatic bag created a pressure of 0.4 atmospheres;

- using V-belt pulleys, the rotation frequency of the rotor was set from 90 to $190 \mathrm{~min}^{-1}$, with a step $\Delta_{1}=20 \mathrm{~min}^{-1}$. Control measurements of the rotation frequency of the rotor were made using a certified digital tachometer; 
- using scales, groups of cobs were formed, which were placed on a feed tray that mimics the orientation device;

- the cobs were fed to the threshing machine with an intensity from 0.4 to $1.4 \mathrm{~kg} \cdot \mathrm{s}^{-1}$ with a step $\Delta_{2}=0.2 \mathrm{~kg} \cdot \mathrm{s}^{-1}$ until the first short-term stops of the rotor appeared and the productivity limit was reached;

- the mass of the threshed material passed through the threshing device was measured;

- statistical processing of the results was carried out and the corresponding graphical dependencies were constructed;

- using the method of graph analytic analysis of the obtained dependencies, the areas of finding intervals of rational values of the active factors were set. The obtained areas were narrowed by experimentally searching for threshing modes that provide the minimum amount of grain remaining on the cobs after threshing, and minimum amount free grain in threshed cobs coming out in the unloading window;

- using scales, the mass of threshed grains that passed into the grain bunker of the threshing device was determined in each experiment conducted on modes that provide rational productivity;

- the remaining grain on the cobs after threshing was finally threshed by hand and weighed;

- the free grain was separated from the threshed cobs and weighed;

- the mass of grains in the grain bunker was compared with the mass remaining on the cobs after threshing and the mass of free grain in threshed corn cobs;

- statistical processing of the results was carried out and the corresponding graphical dependencies were constructed.

\section{Results and discussion}

The maximum possible productivity was determined by the maximum value of the mass of corn cobs that the experimental axial-rotary threshing device is able to process in a set time without shortterm rotor stops. This is how the efficiency of the threshing device was evaluated under theoretically calculated conditions of loading the threshing chamber.

The results of the experimental study of the productivity of the threshing device are presented in the form of graphical dependencies (Fig. 2).

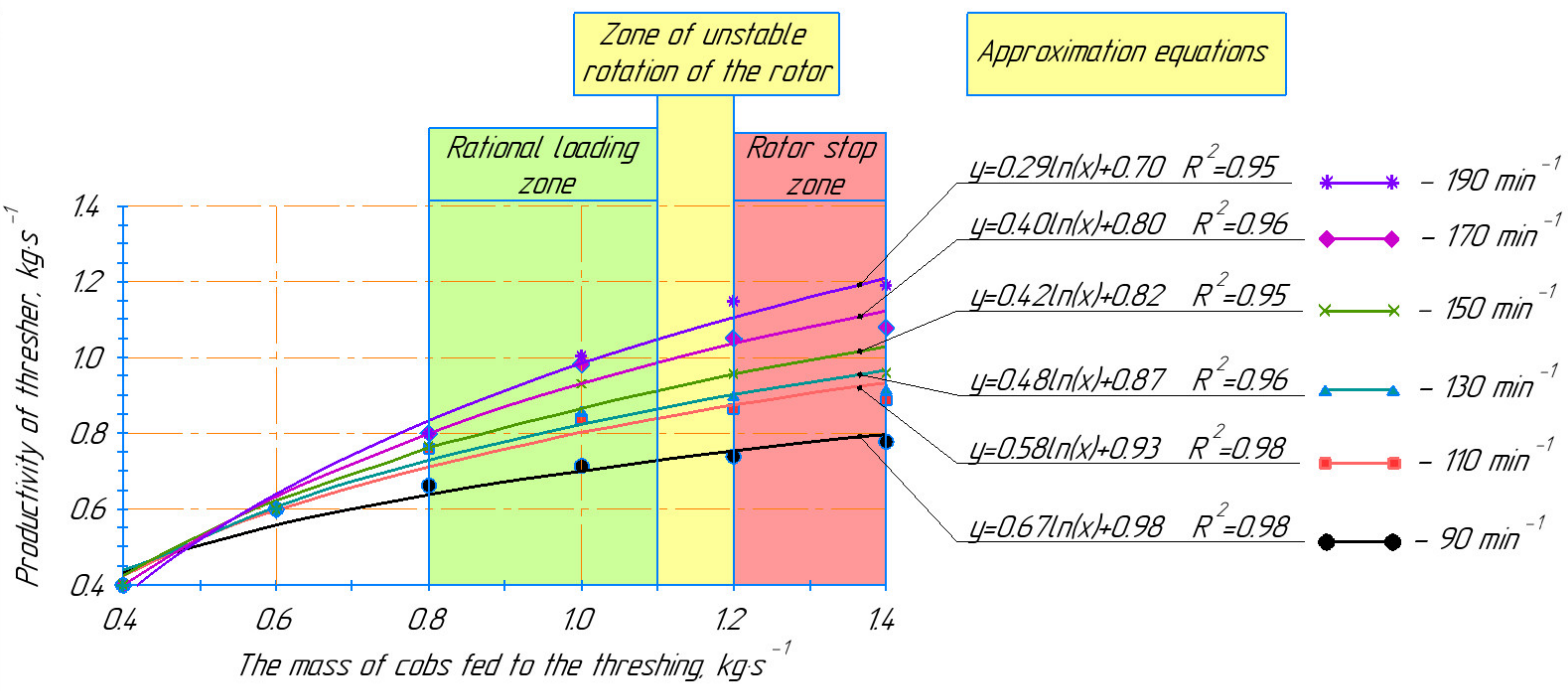

Fig. 2. Results of the experimental study of axial-rotary threshing device productivity

Graphical dependencies (Fig. 2) show that the change in the productivity of the threshing device with increasing in the mass of corn cobs fed to the threshing occurs according to the logarithmic dependence with an approximation accuracy of more than $95 \%$. 
The analysis of graphical dependencies showed that the area of finding rational values of the rotor speed is limited by the interval $150-190 \mathrm{~min}^{-1}$, while the value of rational productivity is within the range of $0.8-1.1 \mathrm{~kg} \cdot \mathrm{s}^{-1}$.

In these modes, the space of the threshing chamber is evenly filled with threshed corn cobs, the pins work across the entire surface of the pneumatic adaptive deck acting on the grain with a rational force of 35-55 N, the cobs do not form compacted areas, the grain is quickly removed from the threshing chamber to the grain bunker, and the threshed cobs are effectively discharged through the unloading window. In addition, the main mass of the threshed cobs does not collapse longitudinally from their rods and does not clog the slots of the relief deck [6; 7].

Clarification of previously established intervals of variation of the experiment factors was carried out on two qualitative indicators: the first of which is the amount of grain remaining on the cobs after threshing, the second is the amount of free grain in the threshed cobs [8-11].

The study of quality indicators of threshing was carried out at an average value of rational productivity of $1 \mathrm{~kg} \cdot \mathrm{s}^{-1}$. The rotor speed was set to 150,170 , and $190 \mathrm{~min}^{-1}$. The results of the experimental study of the first qualitative indicator are presented in the form of diagrams (Fig. 3).

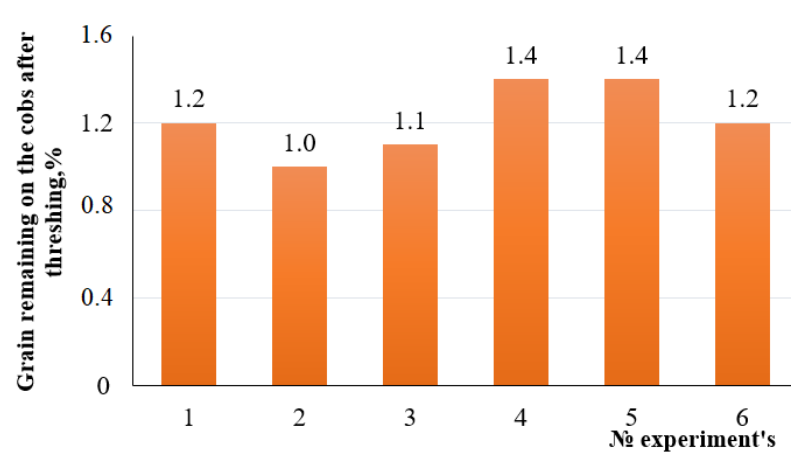

a)

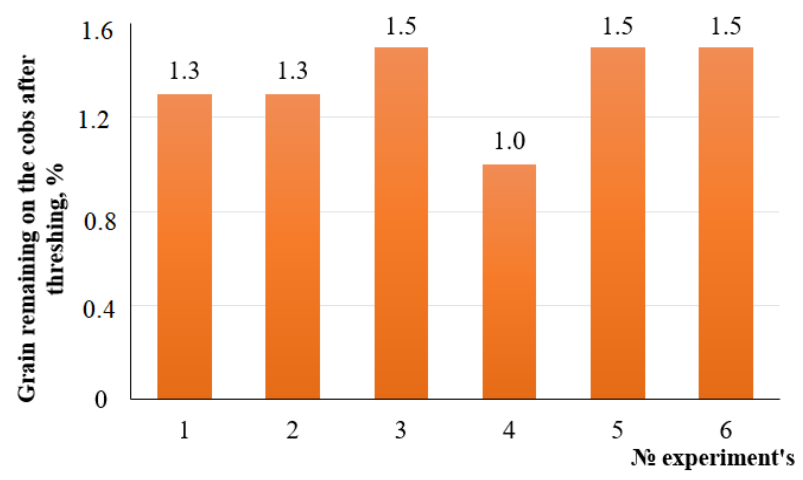

b)

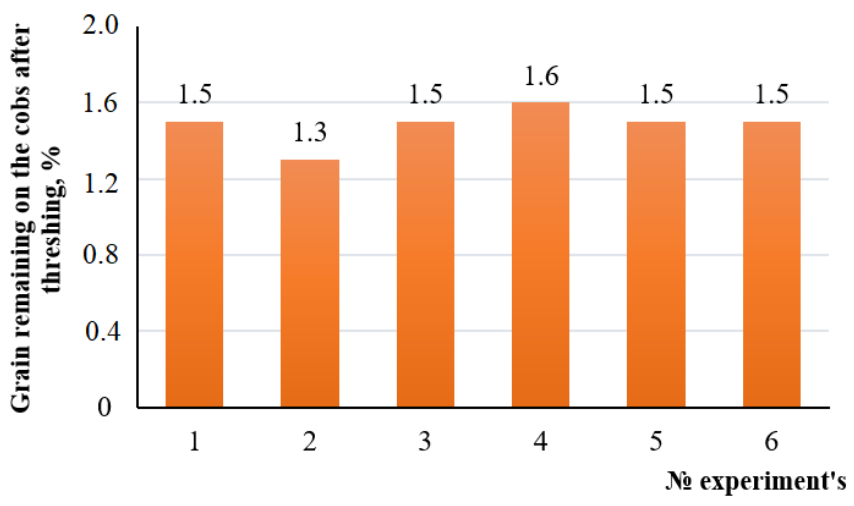

c)

Fig. 3. Results of the experimental study of the first quality indicator of threshing:

$$
\mathrm{a}-190 \mathrm{~min}^{-1} ; \mathrm{b}-170 \mathrm{~min}^{-1} ; \mathrm{c}-150 \mathrm{~min}^{-1}
$$

At all studied rotor speeds, the amount of grain remaining on the cob after threshing does not exceed the permissible value of $1.5 \%$. This is due to the fact that at these speeds of rotation in the threshing chamber a rational mode of impact and friction is provided, in which the connection of the grain with the cob is effectively destroyed. In addition, the analysis of the diagrams shows that it is impractical to reduce the rotation speed below $150 \mathrm{~min}^{-1}$, since at this frequency the upper limit of the values of the studied quality indicator of threshing is reached.

The amount of free grain in the threshed cobs should be minimal, and the sum of the two quality indicators should not exceed the critical value of $2.5 \%$, while ensuring a confidence probability of 0.95 .

The results of the experimental study of the second qualitative indicator were obtained under conditions similar to the previous experiment and are presented in the form of diagrams (Fig. 4). 
Analysis of the diagrams shows that at a rotor speed of $190 \mathrm{~min}^{-1}$, the amount of free grain in the threshed cobs significantly exceeds the permissible value. The reason for this is that at this rotation frequency of the rotor, the grain does not have time to pass into the bunker of the threshing device under the action of its own weight. As a result, the mass of the threshed cobs and the air flow created by the rotor blades of the thresher push the free grain into the discharge window.

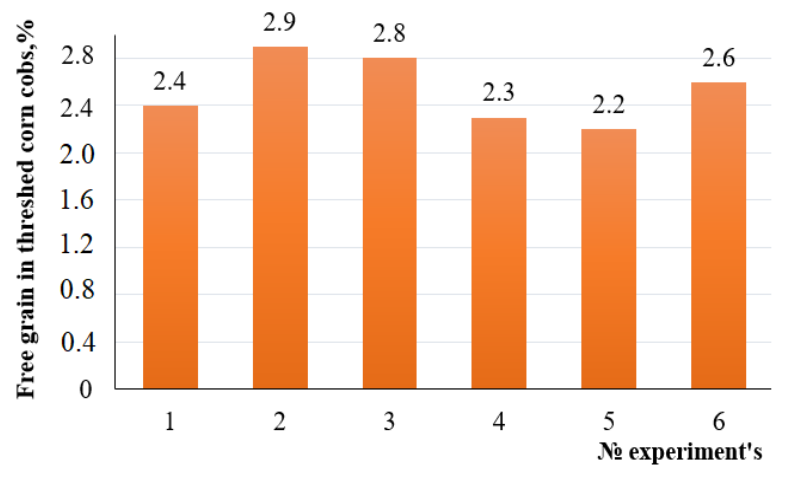

a)

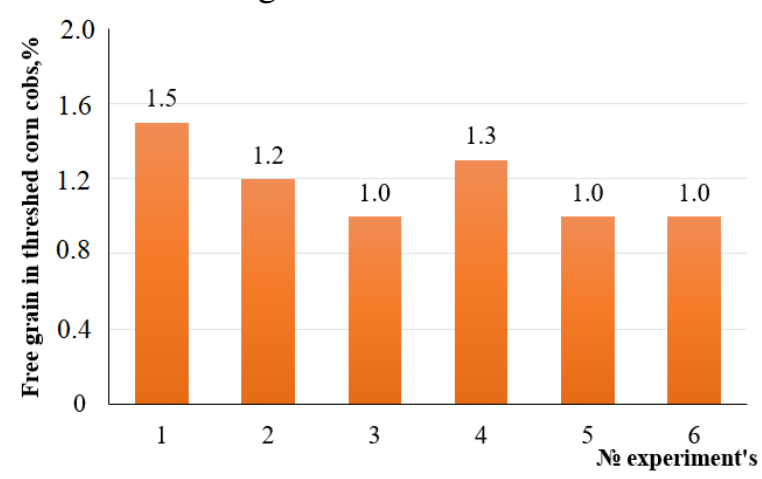

b)

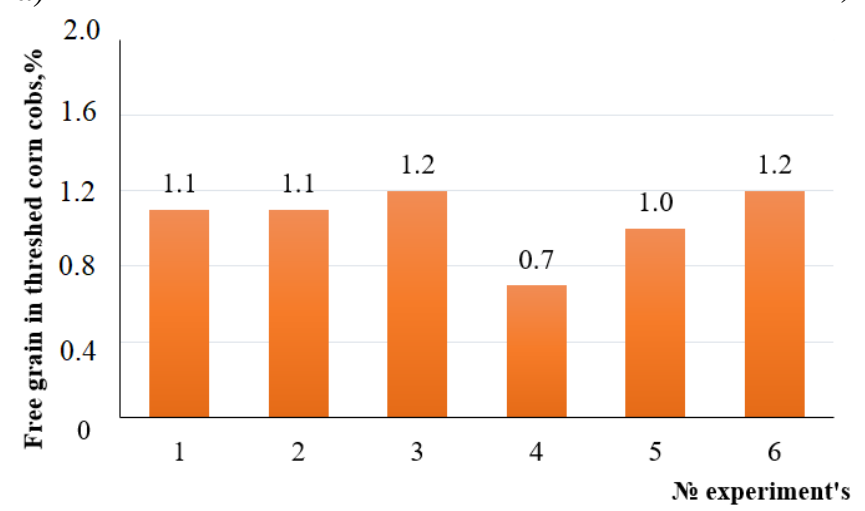

c)

Fig. 4. Results of the experimental study of the second quality indicator of threshing: $\mathrm{a}-190 \min ^{-1} ; \mathrm{b}-170 \min ^{-1} ; \mathrm{c}-150 \mathrm{~min}^{-1}$

At a rotation frequency of the rotor of 150 and $170 \mathrm{~min}^{-1}$ this effect is not observed and the amount of free grain in the threshed cobs is $1.04-1.16 \%$. Therefore, the rational range of rotation frequency of the rotor is narrowed to the limits described above.

To drive the rotor, a gear motor with an electric motor of $2 \mathrm{~kW}$ was used. In a rational range of rotation frequency of the rotor and with a rational feed, the electric motor operated in nominal mode, which was controlled by a certified set of electrical measuring equipment.

Under these conditions, the energy intensity of the threshing process was in the range of 0.5$0.7 \mathrm{kWh} \cdot \mathrm{t}^{-1}$, which is $30 \%$ less than in the serial samples of modern threshers [4].

Currently, Russia, the European Union and China are mass-producing roller threshers of seed corn. It is believed that they provide a minimum of damage to the grain during threshing. However, roller threshers have low productivity, which is a significant disadvantage. The performance of the experimental threshing device is $20 \%$ higher than the maximum possible performance of the most effective roller thresher described in the scientific work [8], while the potential of the experimental threshing device is not exhausted.

The results obtained allow us to determine the basic values of the active factors, when planning and conducting multi-factor experiments aimed at optimizing the technological and design parameters of the threshing device under study, providing not only high productivity and high- quality separation of grain from the cobs, but also minimizing its macro - and micro-damages.

Obtaining minimal damage to the seed grain during threshing is an important scientific and technical task. Therefore, the research carried out is promising and has the potential for further development. 
The results of the research prove the efficiency of the experimental axial-rotary threshing device with a pneumatic adaptive deck. The technological and qualitative indicators of operation of this device confirm the feasibility of its use for threshing cobs of seed corn.

The obtained result is the basis for the upcoming single -and multi- factor experiments to determine threshing modes that provide a minimum of macro-and microdamages to the grain. Further study of this process will allow us to obtain a number of experimental and design data, the introduction of which in production will give a positive practical and economic effect.

\section{Conclusions}

1. The design of the axial-rotary threshing device with a pneumatic adaptive deck minimizes grain losses during threshing.

2. In the experimental design of the threshing device, the rational ones are:

- rotation frequency of the rotor from 150 to $170 \mathrm{~min}^{-1}$;

- feed of cobs for threshing from 0.8 to $1.1 \mathrm{~kg} \cdot \mathrm{s}^{-1}$.

3. With a rational rotation frequency of the rotor and effective loading of the threshing chamber is provided:

- the amount of grain remaining on the cobs after threshing $1.5 \%$;

- the amount of free grain in threshed cobs is $1.16 \%$.

4. The energy intensity of the corn cob threshing process in the axial-rotary threshing device with a pneumatic adaptive deck is $30 \%$ less than in the serial counterparts.

5. The design is promising and requires expanding the field of experimental research on the indicator of macro-and microdamages to grain.

\section{References}

[1] Bakharev D., Volvak S., Pastukhov A. Bionic principles of designing threshing and separating systems for corn cobs: monograph. Publishing House of FSBEI HE Belgorod SAU, Maysky village, 2018. 168 p. (In Russian).

[2] Barać S., Vuković A., Milenković B., Biberdžić M., Dimitrijević A. Qualitative analysis of wheat combine harvester work effects in rye harvest. Research Journal of Agricultural Science, 43(1), 2011, pp. 273-282.

[3] Masek J., Kumhala F., Novak P., Fic T. Influence of different trashing system design on grain damage. Proceedings of International Conference "Engineering for Rural Development 2016" May 25-27, 2016, Jelgava. Latvia, pp. 756-761.

[4] Masek J., Novak P., Jasinskas A. Evaluation of combine harvester operation costs in different working conditions. Proceedings of International Conference "Engineering for Rural Development 2017" May 24-26, 2017, Jelgava. Latvia, pp. 1180-1185.

[5] Gu R.I., Huang R., Jia G.Y., Yuan Z.P., Ren L.S., Li L., Wang J.H.. Effect of mechanical threshing on damage and vigor of maize seed threshed at different moisture contents. Journal of Integrative Agriculture, 18(7), 2019, pp. 1571-1578.

[6] Bakharev D., Pastukhov A., Volvak S., Sharaya O. The substantiation of deck parameters of the rotary threshing device. Proceedings of International Conference "Engineering for Rural Development 2019” May 22-24, 2019, Jelgava. Latvia, pp. 481-486.

[7] Pastukhov A., Bakharev D. Structural model of coarse-grained mass, consisting of corn cobs. Traktori i pogonske mašine. Tractors and power machines. Vol.23, No.1/2, p.1-89, Novi Sad, Dec. 2018, pp. 36-42.

[8] Petunina I. Cleaning and threshing corn cobs. Krasnodar: KubSAU, 2007. 525 p. (In Russian).

[9] Kurasov V.S., Kutseev V.V., Samurganov E.E. Mechanization of work in breeding, variety testing and primary maize seed production. Krasnodar: KubSAU, 2013. 151 p. (In Russian).

[10] Fu J., Chen Z., Han L., Ren L. Review of grain threshing theory and technology. International Journal of Agricultural and Biological Engineering. Vol. 11 No.3, May 2018, pp. 12-20.

[11] Steponavičius D., Kemzūraitė A., Kiniulis V., Zokaitis K. Analysis of corn ears movement within the threshing crescent using high-speed recording method. Journal of Measurements in Engineering, 5(4), 2017, pp. 240-248. 